\title{
Directed Patrol for Preventing City Centre Street Violence in Sweden - A Hot Spot Policing Intervention
}

\author{
Louise Frogner • Henrik Andershed • Odd Lindberg • \\ Marcus Johansson
}

Published online: 14 February 2013

C The Author(s) 2013. This article is published with open access at Springerlink.com

\begin{abstract}
This study examines a hot spot policing intervention where private security guards patrolled a specific area in the city centre of a mid-sized Swedish town during summer weekend evenings and nights, aiming to reduce the number of reported street violence incidents. A follow-up of the intervention, using previous years as a control was conducted to measure changes in the number of street violence rates before and during the intervention. The results show non-significant decreases in the number of reported street violence incidents during the intervention. The results can be interpreted in at least two ways: that the intervention had no effects; or that the small, but non-significant decreases observed, are indeed small effects that can be strengthened by modifying the implementation of the intervention. An additional analysis shows that the changes in crime rates are larger at times when the guards adapted a stricter hot spot policing approach, which indicates that with a more structured implementation of the intervention it might be possible to see larger effects.
\end{abstract}

Keywords City centre $\cdot$ Directed patrol $\cdot$ Hot spot policing $\cdot$ Private security guards $\cdot$ Public places $\cdot$ Street violence

\section{Introduction}

During the past decades different approaches for preventing crime, focusing on high crime places rather than on criminally active individuals have emerged. One such approach is so called hot spot policing. This approach implicates that interventions are directed at small

L. Frogner $\cdot$ H. Andershed $\cdot$ O. Lindberg

Örebro University, Örebro, Sweden

M. Johansson

Örebro County Police, Örebro, Sweden

L. Frogner $(\bowtie)$

Institutionen för JPS, Örebro universitet, 70182 Örebro, Sweden

e-mail: louise.frogner@oru.se 
geographical places, such as addresses or street segments, with relatively high crime rates (Braga and Weisburd 2010b; Groff et al. 2010; Spelman 1995). There are several different methods for doing hot spot policing, methods like increasing the presence of uniforms (directed patrol), raids or making physical changes in a place (Braga 2001; Taylor et al. 2011). The present study is a follow-up of a hot spot policing intervention using increased patrolling by private security guards in order to prevent street violence in the city centre of a medium-sized Swedish city. ${ }^{1}$ The main objective is to see whether the number of reported street violence decreases during the intervention as this was the purpose of the intervention. Several attempts using patrolling security personnel in efforts aiming to reduce alcoholrelated violence and disorder in city centres have been implemented in Swedish cities throughout the past decades. There are, however, no proper effect evaluations of these attempts reviewed and published internationally. Consequently, there are yet no conclusions to be drawn concerning the effectiveness of the use of security guards in order to prevent friction violence in city centres in Swedish conditions. Also, research results from hot spot policing interventions in general are scarce outside America, and directed patrol by security guards in particular, is a rare preventive measure in this area of research.

\section{Targeting Problems and Places}

It is not a new assertion that the distribution of crime varies between cities, neighbourhoods or districts. Shaw and McKay (1942) concentrated on one, in particular, influential pattern concerning the importance of places in criminological research, namely that crime rates in different neighbourhoods tended to be stable over time. Today, criminological theories still stress the importance of this fact, taking the knowledge a step further in looking at the distribution of crime on a micro-level, focusing on small geographical units of analysis such as specific addresses or street segments (Braga and Weisburd 2010b; Groff et al. 2010; Eck and Weisburd 1995; Spelman 1995). Later studies have shown that variations in crime rates exist not only between neighbourhoods or districts, but that large differences can be seen even within a limited area. Small areas with consistently high crime rates have been identified (Sherman et al. 1989; Weisburd et al. 2004; Weisburd and Green 1995), showing that a small amount of places account for a large amount of crime reported in a city or a neighbourhood (Sherman et al. 1989). When crime rates in small places, so called microplaces, are relatively high in relation to crime rates in the city, neighbourhood or district where this place is located, these places are also referred to as hot spots of crime (Braga and Weisburd 2010b; Eck and Weisburd 1995; Groff et al. 2010; Spelman 1995). The knowledge of micro-places of crime has resulted in a new idea concerning "criminal careers of places" (see e.g. Braga and Weisburd 2010b; Eck and Weisburd 1995; Groff et al. 2010; Spelman 1995), serving as a foundation for crime prevention measures aimed at places. The relation between places and crime has repeatedly been scientifically established and has resulted in an increasing use of place-based crime prevention methods. Theories about "criminal career of places" (Braga and Weisburd 2010a; Sherman 1995; Sherman et al. 1989; Spelman 1995; Weisburd et al. 2004) imply that some places naturally provide better conditions for criminal activities than others, depending on factors like the physical formations of the place (e.g. dark corners versus well lit places) and absence or presence of certain elements (e.g. people

\footnotetext{
${ }^{1}$ We consider the intervention a hot spot policing intervention as the target is very specific places with high crime rates and because the security guards have similar rights to intervene as the public police. See further description of the intervention later in the text.
} 
or cameras that increase the perceived risk of getting caught). The idea of focusing crime prevention efforts on places derives from assumptions about how people go about in their everyday life and the ways in which people make rational decisions based on the conditions present in the surroundings (Clarke and Cornish 1985; Cohen and Felson 1979). Thus, the dynamics of a place is pivotal when designing place-based crime prevention interventions. What elements in the immediate vicinity might influence people's decision to commit a crime? How can the settings be manipulated in order to prevent crime?

Violent crime, in particular street violence, which is the crime type of interest in this study, is an example of how crime often clusters in space and time, creating hot spots. Clustering of street violence particularly occurs in areas encircling many entertainment establishments such as restaurants, pubs and nightclubs (Block and Block 1995; Brå 2011; Roncek and Maier 1991; Wikström 1995). As such, alcohol-related street violence is a type of crime that is highly dependent on location (in or around alcohol-serving establishments) and should therefore be likely to gain from the use of place-based crime prevention methods.

\section{The Example of Street Violence in City Centres}

Street violence, i.e. physical assaults or battery taking place out in the streets in public places is a type of violent crime that commonly occurs in city centres in relation to night time establishments serving alcohol. City centres, because of the large amounts of drinking establishments, such as pubs and restaurants and nightclubs, create consistent circumstances for violent crime as they on a regular basis attract a significant quantity of people as well as contributing to the alcohol intoxication level (c.f. Block and Block 1995; Eck and Weisburd 1995; Eisner and Wikström 1999; McMurran 1999; Wikström 1995).

Street violence in relation to alcohol-serving establishments is often dependent on the situation, and has previously been referred to as friction violence. Friction occurs in situations where people interact and someone perceives that they are being interfered by others, and as a result feel provoked. In these situations alcohol intoxication often work as a facilitator of violence (see e.g. Chermack and Giancola 1997; Collin and Schlenger 1988; McMurran 1999). As a result of situations where friction occurs, aggression and even violence can emerge (Wikström and Treiber 2009). Areas with many alcohol-serving establishments in combination with people consuming alcohol can, and will, cause these situations of friction, frustration, aggression, and in extension even violence, to occur in public places (Block and Block 1995; Eck and Weisburd 1995; Eisner and Wikström 1999; McMurran 1999; Wikström 1995). This, in theory, makes public places in relation to these types of establishments well suited for place-based interventions aiming to reduce street violence, as we know when and where situations of friction very likely will arise.

\section{Hot Spot Policing}

Hot spot policing, i.e. focusing various crime preventive efforts on small, micro-level places, is an approach for crime prevention efforts that in the literature seems promising, but not without exceptions. Hot spot policing shows fairly positive outcomes on reducing social disorder and crime, as several studies on this already widely spread policing approach states that focused police interventions seems to be effective for controlling social order, preventing crime and to ensure public safety (Braga 2001, 2005; Braga and Bond 2008; Braga et al. 1999; Braga and Weisburd 2011; Weisburd and Eck 2004). In seven out of nine studies selected for a Campbell Collaboration review (Braga 2001, 2005) substantial reductions of crime and disorder in hot spots were established. The review displays various hot spot 
policing tactics for addressing high crime places (hot spots), for example tactics like directed patrol (increased presence of uniforms, i.e. police or security guards), place managing, traffic stops and raids (see e.g. Braga and Weisburd 2010b; Taylor et al. 2011; Weisburd and Braga 2006). The studies in the Campbell Collaboration review (Braga 2001) showed support for various tactics used in hot spot policing. Directed patrol has had significant effects on all crime in a hot spot with between a 6 and $13 \%$ larger decrease in crime rates in targeted areas compared to control areas (Sherman and Weisburd 1995). Hot spot policing also has had effects on drug related crime. Decreases with as much as $92 \%$ larger decreases in intervention areas than in a non-equivalent control area has been detected (Smith 2001). Also, frisks (i.e. searching peoples outer clothing for contraband, such as guns or drugs) during traffic stops decreased gun crime with $49 \%$, compared with a non-equivalent control beat (Sherman et al. 1995). However, there are examples where hot spot policing efforts, despite the previously demonstrated crime preventive effects, have not proved useful. While presenting significant effects on crime in general as a result of a directed patrol intervention, the results of the Minneapolis Hot Spots Patrol Program (Sherman and Weisburd 1995) also described the detected decreases as "modest" with reductions in crime calls ranging from 6 to $13 \%$. The Minneapolis RECAP program (Sherman et al. 1989) showed no significant reductions in calls for service to the police as a result of problem-oriented interventions in hot spots, and no noteworthy differences in crime calls were detected in an Australian hot spot intervention using POP interventions (Criminal Justice Commission 1998). Hence, hot spot policing approaches apparently display varying results in research. It is also essential to note that the main part of previous studies has been conducted in larger cities, mostly in America, and that the generalizability to other countries and smaller cities is less clear. In summary, hot spot policing appears to be a versatile crime prevention method useful in various situations and on various types of crime, with some exceptions. As research results are not consistent, and in some contexts even lacking, more research is needed in order to establish what types of interventions are useful on what types of crime and in what context.

\section{Directed Patrol and Violent Crime}

One commonly applied method in the hot spot policing approach is directed patrol, i.e. increased presence of uniforms, such as police or security guards, in a place. Studies on directed patrol and alcohol-related violent crimes, which is the focus of the present study, are, however, hard to find. Existing studies of alcohol and violence are often focused on the relation between the two (Block and Block 1995; Chermack and Giancola 1997; Graham et al. 1998; Plant et al. 1977), on crimes committed inside pubs and clubs rather than outside in public places (Homel and Clark 1994), or on interventions targeting alcohol-related violent crime through information campaigns and education for staff and security personnel to encourage responsible beverage serving and to handle public intoxication among people (Felson et al. 1997; Homel and Clark 1994; Homel et al. 1997).

Directed patrol in hot spots of crime has shown mixed results in regards to crime prevention. Some evaluations have been carried out on directed patrol in micro places, some of them targeting violent crime in large. Significant reductions of crime and disorder in general (calls for service) in hot spots due to increased police presence have been established (Ratcliffe et al. 2010; Sherman and Weisburd 1995). In Philadelphia, a directed patrol intervention resulted in a $23 \%$ larger decrease of violent crime in the intervention hot spots than in the control hot spots (Ratcliffe et al. 2010). One further conclusion from this randomized controlled study is that violent crime in a hot spot needs to initially reach a threshold level in order to display statistically significant results of any intervention. In the 
Philadelphia case, the threshold was found to be six reported violent crimes in a three monthperiod (Ratcliffe et al. 2010). With regards to these results, the researchers discuss the importance of dosage and spatial concentration in relation to intervention effectiveness, stating that if these elements are fundamental for a place-based intervention to have positive effects on crime, larger areas and/or a low number of officers patrolling a given area might reduce the effectiveness (Ratcliffe et al. 2010). In Flint, Michigan, foot patrols were implemented on a macro-level, in a number of neighbourhoods, as opposed to targeting smaller, micro-places which is the case in hot spot policing, in order to reduce crime in general (Trojanowicz 1986). The results indicated that the intervention had positive effects on both crime and feelings of safety in the included neighbourhoods, but with substantially weaker effects on reported crime in comparison to previously mentioned evaluations, showing a decrease of mere $8.7 \%$ in intervention areas, compared to non-equivalent control areas (Trojanowicz 1986). It might be feasible to relate the results of the Flint study to the increased size of the intervention area, as micro-level interventions tend to show larger decreases of reported crimes (Ratcliffe et al. 2010). This assumption might be particularly true if adopting the micro-level approach that hot spot policing build its foundation upon.

There are also studies that show small, non-significant decreases in crime rates, due to directed patrol interventions. An evaluation of a 90-day directed patrol intervention aiming to prevent street violence in Jackson, Florida (Taylor et al. 2011) assigned 120 identified hot spots to 60 patrols 5 days a week. Other hot spots, divided into two other groups, received a problem-oriented intervention or a control condition of no intervention. This study measured crime rates during the intervention period and for a 90-day post-test period, looking at residual effects on crime rates in the included hot spots after the intervention. The results showed a decrease of violence in the directed patrol-hot spots, compared to the control area, ranging from 4 to $20 \%$ during the post-test period, but the results were not statistically significant (Taylor et al. 2011). Several feasible reasons for the modest results of the directed patrol interventions were discussed, reasons such as officers straying from their patrol area, the limited intervention period, and varying dosage of patrol. The expressive nature of violent crime is mentioned as a possible contributing factor to weaker effects of place-based interventions (Taylor et al. 2011). This suggestion can also be related to the weaker effects of interventions targeting violent crimes in the Campbell Collaboration review (Braga 2001, 2005). In a Philadelphia study officers were placed in hot spots $24 \mathrm{~h}$ a day 7 days a week for 4 months as a mean to prevent drug-related and violent crimes (Lawton et al. 2005). The intervention showed mixed results. In the respective neighbourhoods the effects of the intervention proved to be statistically significant, but the intervention had no apparent effects on the city's overall drug or violent crime statistics.

With regards to the discussions about dosage of patrol, a study has also been conducted on the necessary amount of police presence in hot spots in order to achieve preventive effects (Koper 1995), based on data from observations during a one-year intervention in Minneapolis (see the Minneapolis Preventive Patrol Experiment, Sherman and Weisburd 1995). Dosage of police presence was divided into categories created from time spent in hot spots and the related effects on crime calls, and then comparing the results to those of a drive-by patrol. The results indicated that between 11 and $15 \mathrm{~min}$ is the ideal time spent in a hot spot of crime (Koper 1995). The conclusions are that patrol stops reaching the threshold level of 11 min leads to statistically significant residual deterrence, i.e. longer time periods without disorder, in comparison with drive-by patrols. Also, after $15 \mathrm{~min}$ the effects of police presence seems to not be statistically significant in comparison to those of a drive-by (Koper 1995).

The varying research results concerning hot spot policing and directed patrol illustrates the potential of the method, but a need for more knowledge also emerges. Hot spot policing 
seems to be a versatile approach for preventing crime useful in various contexts and on various types of crime. However, as these positive results are not without reservation, particularly concerning directed patrol and violent crime, more knowledge is needed to establish the usefulness of this kind of intervention in different contexts.

\section{Aim of the Present Study}

Existing research on hot spot policing and directed patrol tells us that there is a lot of potential in these crime prevention approaches. However, gaps in this knowledge emerge when looking closely at different methods in relation to different crime types and different contexts. There is still much to find out of what works, under what circumstances and for whom. It is therefore desirable to continue testing directed patrol interventions in different contexts and on different types of crime. The objective of this study was to evaluate a hot spot policing intervention implemented in the city centre of the Swedish city of Örebro, called the $\S 3$ project, ${ }^{2}$ which through directed patrol by uniformed private security guards aimed to reduce street violence.

\section{Implementation of the $§ 3$-project}

The run time of the $\S 3$ project was set to the first weekend of June through the last weekend of September the years of 2010 and 2011. The intervention consisted of private security guards (PSG's) patrolling a limited area $\left(0.7 \mathrm{~km}^{2}\right.$ or $\left.1 / 4 \mathrm{mi}^{2}\right)$ encompassing several known hot spots of street violence within the city centre of Örebro, Fridays and Saturdays between 8 p.m. and 4 a.m. Initially 20 guards of different ethnic backgrounds, four women and 16 men, were recruited for participation in the project. Sixteen guards (two women) in total executed the intervention patrolling four at the time, in pairs of two, each work session.

\section{Settings}

Nightclubs and bars (see the smaller dots in the map in Fig. 1.) in Örebro open at different times during the night, but close simultaneously at 2 a.m., leaving large amounts of people lingering in the streets waiting for transportation or food from late-night restaurants. There are also a few main hot spots for street violence according to police crime statistics within the intervention area. The larger dots on the map in Fig. 1 mark main hot spots of street violence in Örebro city, squares adjacent to nightclubs, pubs, night-open restaurants and bus stops (c.f. Brå 2011).

\section{Instructions}

The PSG's were instructed to be visible, focus on positive relations with the public and to interfere when needed, in order to prevent violent crime and fend disorderly behaviour. In order to achieve visibility the guards wore reflective vests, with "security guard" printed in large letters, and their ordinary badges with tag numbers. However, the PSG's received no particular instructions prior to the intervention concerning for example, the patrol routes during the night, or on how much time should be spent in each hot spot or part of the intervention area. The only clear structure in when the guards were supposed to patrol in a specific location was at the nightclubs' closing hour each work session. All nightclubs in

\footnotetext{
$\overline{2}$ The project is named after $\S 3$ in the Security Stewards Code [Lag (1980:578) om ordningsvakter], the section that regulates the guards' authority to patrol and intervene within a specific area.
} 


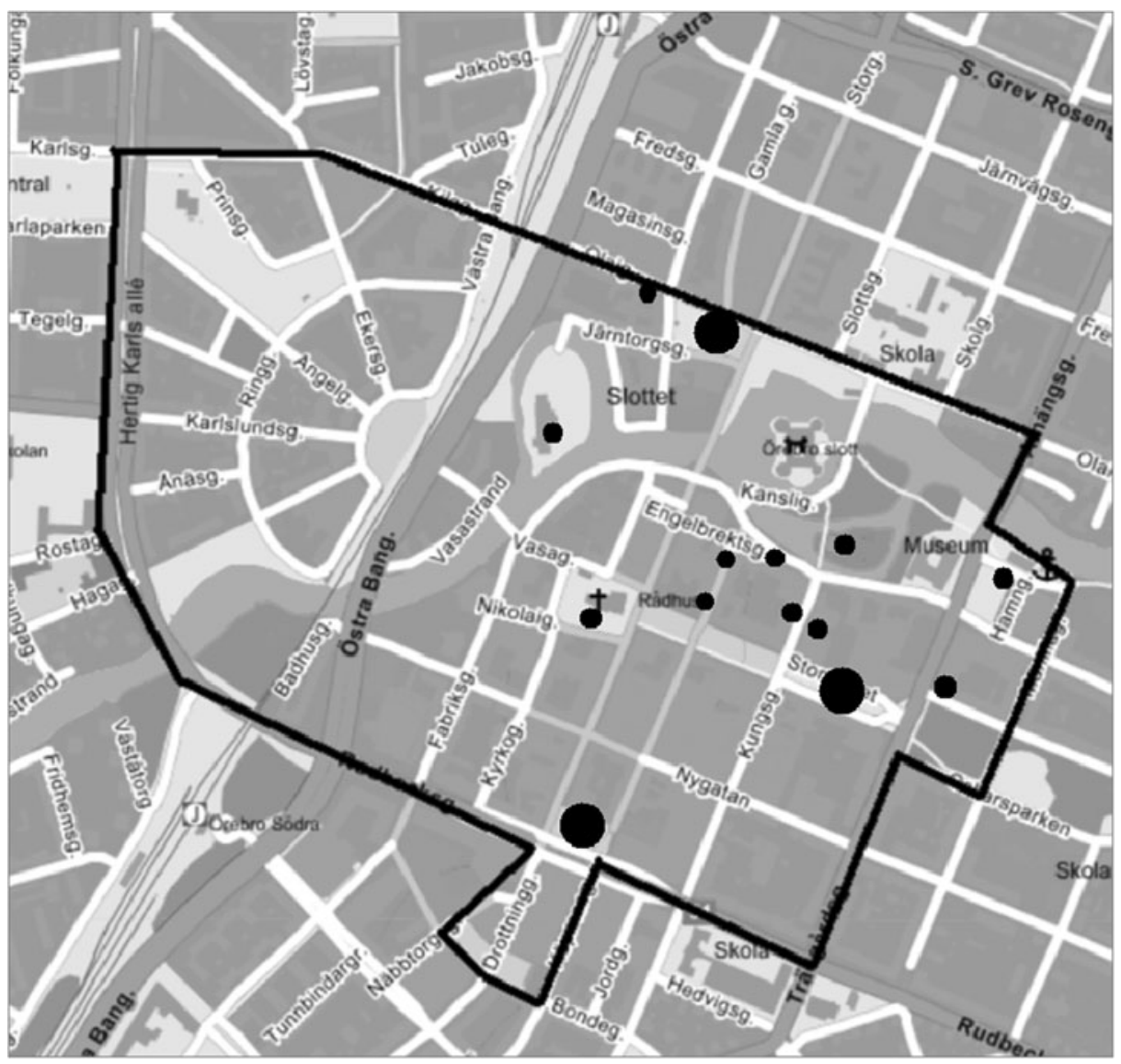

Fig. 1 Map of intervention area with hot spots

Örebro close simultaneously at 2 a.m., sending large amounts of people out into the streets at the same time. By placing themselves in strategic places at closing time the PSG's and the police aimed to cover as many of the hot spots as possible at this time. How this was to be executed was decided from work session to work session as the guards, and any available police patrols, were positioned in set locations when the nightclubs closed, based on the amount of patrons in each place and other factors that (according to their experience) could be an indicator of trouble later on.

One minor difference in the implementation occurred between 2010 and 2011, as in 2011 one pair of guards got access to bicycles in order to move fast when called for, and to more quickly be able to cover large areas in preventive purposes. However, the bicycles were according to the head of the PSG's not used at all in any situations of disorder or violence, but merely made the patrolling a bit swifter in the calmer parts of the intervention area.

Private Security and the Police in Sweden It is not unusual for the police to employ private security agents for crime preventive purposes (Berkley and Thayer 2000). In Sweden, the kind of private security guards used in this project work in close relation to the police at all times, the police being the responsible authority. They receive special, mandatory training 
and education from the police authorities, and wear badges with tag numbers. The police is always in charge for PSG's on duty, and the guards report back to the police by the end of each work session. Their work is regulated primarily by the Security Stewards Code (SSC) as well as by some sections from the Swedish Police Act. The Police Act mainly regulates the PSG's right to wear (and use) arms, such as truncheons, and their authority to remove and apprehend threats to the law and social order. The SSC also stipulates that the guards may be assigned to work in this manner within different areas and establishments, for example in courts, nightclubs, locations for sport and music events and so on. Section 3 of the Security Stewards Code states that the police can, when needed, also grant the PSG's authority to work in areas not mentioned previously in the SSC, such as in our case the entire city centre. Bars, pubs and nightclubs, usually have their own PSG's of this particular type (bouncers) hired, that have the right to intervene inside, and directly outside the entrance of, their nightclub. Their authorization, however, stretches no further than that (c.f. Berkley and Thayer 2000). Thus, the guards commissioned within the $\S 3$ project were used as a complement to the nightclub PSG's, as they were authorized to intervene only outdoors within the designated area in the city centre, and not inside any sort of business establishment.

\section{Method}

\section{Research Design}

We did a follow-up study, comparing crime rates (physical assaults outdoor reported to the police) in the intervention area during the intervention, that is, for June through September 2010 and 2011 between 8 p.m. and 4 a.m. Friday and Saturday nights (the intervention period), with the crime rates of the corresponding period and times of the years 2008 and 2009. Importantly, during 2008 and 2009, no intervention was implemented in this area.

\section{Sample and Data}

The type of crime measured was street violence (physical assaults committed outdoors) within a specific area (the intervention area) in the city centre during the times of the guards' work sessions, Fri-Sat nights 8 p.m. -4 a.m. This crime type was selected as i) it was a main purpose of the intervention to reduce violence in the city centre in relation to opening hours of night-time establishments (this was a decision taken by officers of the municipality of the city of Örebro) and ii) the PSG's were only authorized to intervene outdoors and therefore had no possibility (or purpose) to prevent crime inside any of the bars or nightclubs.

\section{Street Violence in Örebro}

In Sweden, during 2009, almost half (49.5\%) of all reported physical assaults against people over the age of 18, took place outdoors (Brå 2010). Between the years of 2005 and 2009, about 3200 street violence crimes were reported to the police in the entire municipality of Örebro. About $44 \%$ these incidents were committed during Friday and Saturday nights between 8 p.m. and 4 a.m., and almost $30 \%$ of all reported assaults were committed in the city centre ( $1.6 \%$ of the city areal), thus creating a hot spot of street violence. Örebro is a medium-sized Swedish city covering an area of 16.5 square miles, with 107,000 inhabitants of the 630 square miles and 135,000 inhabitants that make up the entire municipality of Örebro, with a city centre that encompasses roughly $1 / 4$ of a square mile. The crime statistics 
for Örebro presented above correspond well with Swedish physical assault crime rates in general (Eksten 2009). A recent report from the Swedish National Council of Crime Prevention (Brå 2011) confirms the existence of hot spots of street violence in Swedish cities, with two to five hot spots with between 26 and $58 \%$ of all reported street violence in the cities examined.

The above numbers show that a large part of all street violence is reported during a very limited time period in a year. Nearly half (44\%) of all street violence is committed Friday and Saturday nights, during June through September, which in other words means that half of all reported street violence is committed in $9.5 \%$ of the entire year. Also, research shows that violent crime tends to increase with warm weather (Cohn 1990, 1996; Rotton and Cohn 2000). This relationship might depend on several various behaviour patterns that change in relation to the weather, such as alcohol-consumption and increased social interaction. It is feasible to assume, that in countries like Sweden, where climatic variables such as temperature and rain or snow fall vary substantially over the year, this relationship might very well be true. This implicates that months of summer should make up hot times, so to speak, and that this period of the year is well-suited for implementing interventions targeting violent crime in public places in Sweden. Because of the lower crime rates during the rest of the year, other time periods than summer were concluded to be irrelevant for comparison. This was the main reason why the intervention period was compared to the corresponding period of previous years, rather than to the months immediately preceding or following the intervention, i.e. a before-after comparison.

\section{Statistical Analyses}

The groups for comparison in this study consist of all weekends between the first weekend of June until the last weekend of September 2008-2011, a total of 68 weekends $(N=68$, $08 / 09 n=34,10 / 11 n=34)$. Even though the crime rates were measured for the exact same areas before and during the intervention, the actual weekends measured differ between the years. Therefore, we chose to treat the intervention group (the weekends of 2010/2011) and the pre-test group (the weekends of 2008/2009) as two independent groups, rather than one and the same group as object for pre- and "during"3-test. Hence, we performed an independent-sample t-test in order to test for changes in crime rates between the two "groups". The weekends of 2008 and 2009 thus made up one group and the weekends of 2010 and 2011 (intervention period) the other group.

In order to conduct a t-test the observations in the groups need to be independent of each other. When comparing crime rates per night in any given week it is highly possible that the number of reported crimes during Friday night correlates with the number of reported crimes during Saturday night, making the observations dependent of each other. There is, however, no reason to believe that this correlation remains over longer time. So, to avoid the risk of the observations being dependent, we used number of reported street violence per weekend as the dependent variable, thus measuring Fridays and Saturdays together. A small part, $4.4 \%$ of the reported crimes in the original data set had to be excluded as information of time and/or place for the incident was not documented.

Possible Confounders We considered some likely confounders. We tested correlation between weather (temperature, rainfall and air humidity) and number of reported street

\footnotetext{
${ }^{3}$ No post-test was conducted as the intervention period is limited to certain months of the year and the feasible time period for a post-test would be the corresponding period of 2012 (without intervention).
} 
violence. Also, the number of establishments with alcohol serving permits within the intervention area was compared over the years. Lastly, we looked at disturbances (construction work) that took place in one of the main hot spots during the entire summer of 2010. The constructions work meant that bus stops, and the otherwise natural flow of people, moved away from the hot spot, which could imply that fewer violent crimes would be committed here, as the number of both potential targets and potential offenders decreased, and with it the risk of friction.

\section{Results}

The graph in Fig. 2 illustrates the means of the numbers of street violence crimes reported in Örebro during summer weekend evenings and nights between the years of 2005 and 2011. It also shows the distribution of these crimes between $\S 3$ area (the intervention area) and the rest of Örebro municipality, outside the intervention area.

As seen in Fig. 2, in the $\S 3$ area, the crime rates have fluctuated since 2005. A decrease in reported violence occurs, and remains, in this intervention area during the intervention periods in 2010 and 2011. However, in the $\$ 3$ area, the lowest levels of street violence reported, prior to the intervention years, was in 2007 and 2008. If lower crime rates than those of 2007 and 2008 were to be reported in 2010 and 2011 (i.e. during the intervention), this would indicate that the intervention might have affected the levels of reported crime. However, as seen in Fig. 1 this is not the case. As for the rest of Örebro municipality, the crime rate increases between 2006 and 2010, and decreases in 2011.

The results of the t-test, $(t(66)=1.07, p>0.05, d=.47,95 \% \mathrm{CI}[-.41,1.35])$, shows that no significant decreases in reported street violence can be ascertained between the two periods of measurement. The $d$ illustrates the mean difference between the two periods and CI shows the upper and lower confidence intervals of the t-value with a confidence level of $95 \%$. The actual crime rates show a decrease of $23.6 \%$ in number of reported physical

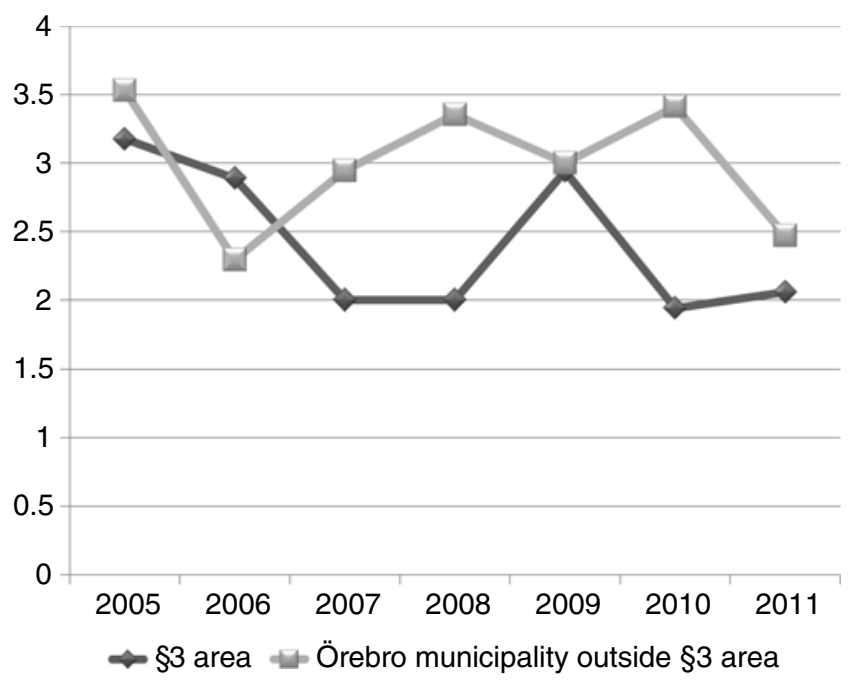

Fig. 2 Number of reported street violence (means) during weekend evenings and nights June-September 2005-2011 
assaults between the two groups (2008/2009 and 2010/2011), but the decrease is not statistically significant.

\section{Considering Potential Confounders}

To consider possible confounders, we correlated number of reported street violence and weather (rainfall, temperature and air humidity) for each year 2008 through 2011, which showed no significant correlations. Thus, it was not necessary to control for this when conducting the main analysis. The number of establishments with alcohol serving permits within the intervention area did not change notably during the years of control, between 2009 and $2011 .{ }^{4}$ The occasional permit was approved, or in some cases retracted, during this period, but these minor changes did not affect the distribution of nightclubs nor the number of valid permits overall, and can therefore be said not to have affected the outcome of this study. Construction work in one of the main hot spots during the summer of 2010 was considered to be a disturbance of the natural flow of people as bus stops were moved during this period. Therefore, for the last analysis, we calculated the share of reported street violence committed at this hot spot in question in relation to all committed street violence in the $\$ 3$ area over the years, which showed no apparent effects on number of reported crimes. Based on these findings we did not test for any of these confounders in our main analyses.

\section{Evidence of Effects When Patrolling was More Structured?}

A supplementary analysis was conducted breaking down results to see if differences were larger at some points during the PSG's work sessions. With the increased structure in the implementation at closing time (2 a.m.), when the guards were deliberately stationed to cover as many hot spots as possible at once, and with the increased number of people in the streets at this hour, the change in crime rates could prove to be larger than the overall change during the intervention, if the PSG's presence actually have effects. That is, differences in crime rates between the two groups, $08 / 09$ and 10/11, could be larger at certain expected time points during the nights. Hence, we divided the work sessions into separate hours $(8$. p.m.-8.59 p.m. = hour 1, 9.p.m. -9.59 p.m. = hour 2 and so on) and performed a two-way ANOVA with hour and year as the independent variables, and number of reported street violence as the dependent variable. Only the hour-group, $\mathrm{F}(7,1072)=15.82, M S E=.22$, $p=.00, \eta=.31$ showed main effect. When holding the other factors fixed, the year-group showed no significant main effect and no significant interaction effects occurred.

Levels of street violence per hours, and by year in the $\S 3$ area, is presented in Fig. 3. The graph shows that the number of reported street violence in the city centre is fairly similar at all hours between the two groups (periods of measuring), except for hour 7, between 2 a.m. and 3 a. m., where the crime rates are lower during the years of interventions (i.e. 2010/2011), as would be expected because of the more structured hot spot patrolling during this hour. However, this difference was not statistically significant. The pattern at 2 a.m., when the PSG's were positioned to cover as many hot spots as possible, is very interesting as this could indicate that with a clearer hot spot policing structure and focus in the implementation, the intervention might have shown different overall results.

\footnotetext{
${ }^{4}$ There are no registers of alcohol serving permits prior to 2009 as the municipal government does not keep these numbers on file as a rule.
} 


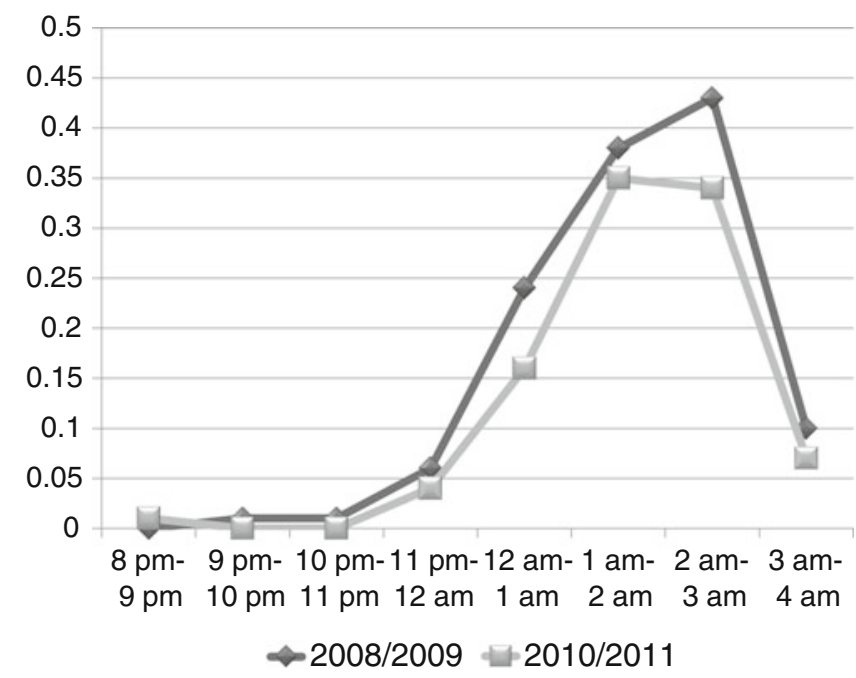

Fig. 3 Number of reported street violence in 3 areas, hour per hour weekends 8 p.m. - 4 a.m. 2008/2009 (control years) and 2010/2011 (intervention years)

\section{Discussion}

The results of the study show no significant changes in the number of reported street violence before and during the hot spot policing intervention using private security guard patrols with the purpose to prevent this type of crime. However, we show indications of effects in that the decreases in reported street violence are larger at certain points in time, when the security guards used a more structured hot spot policing approach. Thus, the conclusions of the evaluation are that either there are no effects of the intervention, or that there are weak but non-significant effects of the intervention, and if implemented differently it may be possible to get stronger effects.

\section{Implementing Hot Spot Policing}

In general, evaluations of hot spot policing efforts show good results with decreasing crime rates (Braga 2001, 2005; Braga and Bond 2008; Braga et al. 1999; Braga and Weisburd 2011; Koper 1995; Sherman 1990; Sherman and Weisburd 1995; Weisburd and Green 1995; Weisburd et al. 2009). However, there are also some previous evaluations of directed patrol interventions that show small or non-significant effects on both crimes in general, as well as on violent crime in particular. In the light of previous research and theories on which placebased crime prevention efforts rest, the non-significant results of the present study are not necessarily surprising. The indication is rather that results might be altered if the intervention was implemented under different circumstances, mainly regarding dosage and structure. The planning and implementation of the PSG intervention is key when discussing the results of the evaluation. Apart from the knowledge of actual crime rates in the city centre the project lacked a scientific knowledge base concerning implementation of this type of crime prevention efforts. This resulted in two general flaws in the implementation: lack of structure in the PSG's task and low patrol intensity/dosage.

Implementation can have a significant impact on the outcome of a program, both when done well and when done badly (Durlak and DuPre 2008). It is very important to know what 
the intervention has contained, all the detailed elements of the program that has been delivered, in order to be able to draw adequate conclusions about the outcomes. One issue in implementing a new intervention is quality, which relates to how clearly and correctly the intervention has been conducted (Durlak and DuPre 2008). Lack of clear structure and instructions on how to execute the task at hand should, logically, make it harder to follow the program as it is unclear what the essential components are. Hot spot policing implicates extensive focus on small, well-limited areas as targets for an intervention. Essential components in one such intervention could therefore, for example, concern where the main hot spots are, how to patrol them and the amount of time to be spent in each hot spot, in order to achieve the desired effects. These factors were never clarified prior to the implementation of the $\S 3$ intervention, increasing the risk that the intervention was not conducted with as good of quality as might have been possible with better structure.

Dosage and patrol intensity are issues that relate to the quality and the structure of the implementation. As mentioned previously, hot spot policing as a crime prevention approach focuses, by definition, on micro-places of crime (Braga and Weisburd 2010b; Groff et al. 2010; Weisburd and Green 1995). In the Örebro $\$ 3$ case, a rather large area $\left(0,7 \mathrm{~km}^{2}\right.$, $1 / 4 \mathrm{mi}^{2}$ ) was included for the intervention. The intervention area in Örebro encircled not only several hot spots, but also several calmer parts without any hot spots of street violence. Since there were no clear, specific guidelines for the PSG's to work according to, there is no way of knowing where they spent time patrolling, how long they spent in each hot spot within the area, if the entire area (all hot spots) was covered to a satisfying level and so on. For example, if both pairs of guards spent a lot of time in the same part of the area this would suggest that significant parts of the city centre were not covered during these times. Large areas and few patrols together give limited dosage of patrolling in each hot spot. This might mean that the amount of patrolling in each hot spot might not reach adequate levels, compared to what is suggested in previous research (Koper 1995; Ratcliffe et al. 2010). The effort in Jackson, Florida (Taylor et al. 2011) led to a decrease of violent crime but had no statistically significant effects; dosage of patrols in hot spots is pointed out as a possible contributing factor to modest results of place-based interventions. Dosage and area size are also brought up in relation to interventions with significant effects in Philadelphia (Ratcliffe et al. 2010). Directed patrol interventions have been conducted on larger areas and showed positive results. In the Michigan evaluation (Trojanowicz 1986) the results show significant effects, but the changes in crime prevalence are not as large as in the other examples, hot spot policing emphasizes micro-places of crime. If fully adopting this idea, area size and intensity of patrolling are important components of place-based interventions. Thus, interventions of this kind implemented on larger areas probably will not show as substantial changes in crime rates, which might be one reason why the $\S 3$ project shows no statistically significant changes in street violence during the intervention.

One thing in this Örebro $\S 3$ study, that might indicate that with better structure in planning and implementation the outcomes could have been different, is the pattern illustrated in the additional analysis of the hour by hour-crime rates. Despite non-significant results when analysing differences in differences at the separate hours, the tendency seems to be that street violence decreases at the clubs' closing time in 2010/2011, where crime increased in 2008/2009. This could mean that increased hot spot policing structure leads to better results, because we see larger decreases in reported street violence when the guards focus their patrolling on micro-places. Or it could simply be an indication that the guards only have the possibility of making a difference out in the streets at specific times during the evening, times when large amounts of people move about outside. The latter thought is also consistent with the concept of alcohol-related street violence as friction crime. Both 
hypotheses indicate that if the implementation were to be more intensively focused on specific hot spots and hot times, this could lead to better outcomes of the intervention, and maybe even statistically significant changes in crime rates. This conclusion would also be consistent with the argument about quality and importance of details and structure when implementing an intervention (c.f.Durlak and DuPre 2008), which strengthens the hypothesis that the lack of structure in the implementation might have affected the outcome.

Another implementation-related issue concerns the type of uniform the directed patrolintervention used in the $\S 3$ project. Even though private security is a common feature in policing today, both private and public, (see e.g. Berkley and Thayer 2000; De Waard 1999; Shearing and Stenning, 1983) their uniforms might simply not have the same deterrent effect as a police uniform, which would then undermine the security guards' authority, making it harder for them to maintain order and perhaps to affect possible offenders. If this is true, the fact that security guards, rather than police, patrolled the city centre, might also have influenced the outcome.

\section{Third Party Policing}

Third party policing implies that the police engage other actors in the community to take part in attempts to control, or prevent, crime (Buerger and Green Mazerolle 1998) and in this way, the current intervention may be taken for a third party policing intervention since the police did engage security guards. However, we would argue that the current project is best framed and defined as a hot spot policing intervention because it targets specific high-crime places and because the security guards in the intervention have the same rights to interfere as the police, and, finally, policing, in the sense of executing social control, is not necessarily done by the police, but can be executed by other actors in society (see e.g. Reiner 2010).

\section{Limitations in the Örebro $\S 3$ Study}

First of all the research design is a limitation. An experimental research design, with randomized sampling and control groups for comparison, is the preferred way of testing for causality when evaluating the outcome of an intervention of some sort. However, this research design is not applicable in all cases. It is, for example, hard to randomly assign place-based interventions to different places, when the key in such interventions is the specific context of a place. It is hard to find equivalent areas for comparison, and almost impossible to find areas that are exactly the same as the intervention area(s) (c.f.Eck 2002). This was an issue in the Örebro $\S 3$ study, making it impossible to do a rigorous, experimental evaluation of the security guard intervention. Also, researchers were involved late in the implementation process and had no possibility to plan an evaluation prior to the intervention, which excluded other types of research designs as well. Late involvement of evaluators was also a contributing factor to the lack of structure and documentation in the intervention, as a rigorous evaluation was not planned for initially by the executors.

A very important issue in place-based crime prevention is displacement. Displacement of crime as a result of a place-based intervention can compromise the results of such an intervention, meaning that crime does, despite lower crime rates in the intervention area, not decrease in total as it just "moves around the corner" (see, e.g. Bowers et al. 2011; Gabor 1990; Guerette 2009; Guerette and Bowers 2009; Hesseling 1994). That is, crime rates decrease in the intervention area as a result of the intervention, but crime rates in surrounding so called catchment areas, increase during the same period. In the $\S 3$ study we had no opportunity to measure any potential displacement effects as surrounding areas do not 
compare to the city centre as places that attract the observed crime type. There are, for example, few or no nightclubs or night-open restaurants in these areas. As a result we did not have access to data needed for an analysis of crime displacement.

In our case it was also a challenge to do before- and after-tests of crime rates in the intervention area, as the intervention time period (summer weekends) stands out during the year as an active period of street violence. As a solution, it would be of interest to measure crime rates in the intervention area during the same time period one summer without intervention, to see whether the crime rates increase without the security guards in place. This has, however, not been possible to do, as the intervention was implemented again during the summer of 2012.

\section{Strengths in the Örebro $§ 3$ Study}

As an experimental effect evaluation was not possible, we decided to use the intervention area as its own control, measuring crime rates in this area prior to, and during, the intervention. When adapting a quasi-experimental approach or doing a follow-up study, which is the case in the present study, it is important to be systematic and to eliminate as many plausible alternative hypotheses as possible (Eck 2002; Farrington 1987). There are some commonly occurring factors that might influence the outcome in non-experimental studies, that need to be paid attention, in order to strengthen the internal validity of the study as much as possible (Farrington 1987), and that we have considered here. First, can the measured decrease in crime simply reflect a normal fluctuation in crime rates? Our results might indicate that this is the case, as the decrease is statistically non-significant. However, the hour-by-hour analysis shows a larger decrease at certain points in time, indicating that better results of the intervention might be possible with a more structured implementation. These indications are in line with previous research on directed patrol interventions. Second, does the outcome reflect differences between different areas, or changes in the intervention area? In the $\S 3$ study we used only one area for comparison. In this area we tested for confounders likely to influence the street violence rates: number of establishments in the city centre with alcohol serving permits, disturbances in hot spots, and weather. The results of these tests showed that the confounders had no implications for the outcomes of the intervention. Third, does the outcome reflect a pre-existing, decreasing trend? We collected data for 7 years (2005-2011, previously presented in Fig. 2), which shows that street violence rates in Örebro has fluctuated during these years, indicating that there was no consistent trend prior to the intervention. Fourth, does the decrease reflect changes in measurement methods? We used police records for reported crime for all years of measuring. However, the human factor is an important part of the police report registers as insufficient documentation concerning place and time could have caused incidents that should be included in the study to be sorted out. In this case $4.4 \%$ of the original data set was excluded due to the lack of information regarding time and place of the crimes in the reports. With the low crime rates these missing data might be enough to have a small impact on the results. Fifth, was the intervention implemented after a period with unusually high crime rates? In 2009 the crime rates were a bit higher than previous years. We handled this by merging data for 2008 and 2009 into the control group, in order to even out some of the fluctuation between the years prior to the intervention.

Proper, experimental, effect evaluations of hot spot policing and directed patrol are scarce in other parts of the world than America. To our knowledge there are no evaluations of security guard interventions aiming to prevent street violence. Even systematic follow-ups of directed patrol interventions in general, with our level of strictness and systematicity, are rare. So, despite the somewhat flawed research design in the Örebro $\S 3$ study, there is a need for studies of this sort, both concerning the type of intervention and the context. 


\section{Future Directions}

The results of the present study touches on questions concerning what works, when and where, that still have not been addressed to a satisfying extent by previous research. Knowledge is still lacking regarding the potential of hot spot policing interventions using directed patrol. In summary, more knowledge is needed, not only regarding what works on what and when, but also about whether hot spot policing is an adequate approach in all hot spots of crime.

Open Access This article is distributed under the terms of the Creative Commons Attribution License which permits any use, distribution, and reproduction in any medium, provided the original author(s) and the source are credited.

\section{References}

Berkley, B. J., \& Thayer, J. R. (2000). Policing entertainment districts. Policing: An International Journal of Police Strategies \& Management, 23(4), 466-491.

Block, R. L., \& Block, C. R. (1995). Space, place and crime: Hot spot areas and hot places of liquor-related crime. In J. E. Eck \& D. Weisburd (Eds.), Crime and place. Crime prevention studies, volume 4 (pp. $145-$ 184). Monsey, NY: Criminal Justice Press.

Bowers, K. J., Johnson, S. D., Guerette, R. T., Summers, L., \& Poynton, S. (2011). Spatial displacement and diffusion of benefits among geographically focused policing initiatives: a meta-analytical review. Journal of Experimental Criminology, 7(4), 347-374.

Brå. (2010). Criminal statistics 2009: Official statistics of Sweden (p. 303). Stockholm: The Swedish National Council for Crime Prevention.

Brå. (2011). Hot spots för brott i sex svenska städer (p. 61). Stockholm: The Swedish National Council for Crime Prevention.

Braga, A. A. (2001). The effects of hot spot policing on crime. The ANNALS of the American Academy of Political and Social Science, 578(1), 104-125.

Braga, A. A. (2005). Hot spots policing and crime prevention: a systematic review of randomized controlled trials. Journal of Experimental Criminology, 1(3), 317-342.

Braga, A. A., \& Bond, B. J. (2008). Policing crime and disorder hot spots: a randomized controlled trial. Criminology, 46(3), 577-607.

Braga, A. A., \& Weisburd, D. (2010a). Editors' introduction: empirical evidence on the relevance of place in criminology. Journal of Quantitative Criminology, 26(1), 1-6.

Braga, A. A., \& Weisburd, D. (2010b). Policing problem places. Crime hot spots and effective prevention. New York: Oxford University Press.

Braga, A. A., \& Weisburd, D. L. (2011). The effects of focused deterrence strategies on crime: a systematic review and meta-analysis of the empirical evidence. Journal of Research in Crime and Delinquency. doi: $10.1177 / 0022427811419368$.

Braga, A. A., Weisburd, D., Waring, E., \& Green Mazerolle, L. (1999). Problem-oriented policing in violent crime places: a randomized controlled experiment. Criminology, 37(3), 541-580.

Buerger, M. E., \& Green Mazerolle, L. (1998). Third-party policing: a theoretical analysis of an emerging trend. Justice Quarterly, 15(2), 301-327.

Chermack, S. T., \& Giancola, P. R. (1997). The relation between alcohol and aggression: an integrated biopsychosocial conceptualization. Clinical Psychology Review, 17(6), 621-649.

Clarke, R. V., \& Cornish, D. B. (1985). Modeling offenders' decisions: A framework for research and policy. In M. Tonry, \& N. Morris (Eds.), Crime and justice. An annual review of research. Vol. 6 (pp. 147-186). Chicago: University of Chicago Press.

Cohen, L. E., \& Felson, M. (1979). Social change and crime rate trends: a routine activity approach. American Sociological Review, 44(4), 588-608.

Cohn, E. G. (1990). Weather and crime. British Journal of Criminology, 30(1), 51-64.

Cohn, E. G. (1996). The effect of weather and temporal variations on calls for police service. American Journal of Police, 15(1), 23-43.

Collin, J. J., \& Schlenger, W. E. (1988). Acute and chronic effects of alcohol use on violence. Journal of Studies on Alcohol, 49(6), 516-521. 
Criminal Justice Commission (1998). Beenleigh calls for service project: evaluation report. Brisbane: Australia.

De Waard, J. (1999). The private security industry in international perspective. European Journal on Criminal Policy and Research, 7(2), 143-174.

Durlak, J. A., \& DuPre, E. P. (2008). Implementation matters: a review of research on the influence of implementation on program outcomes and the factors affecting implementation. American Journal of Community Psychology, 41(3-4), 327-350.

Eck, J. E. (2002). Learning from experience in problem-oriented policing and situational prevention: The positive functions of weak evaluations and the negative functions of strong ones. In N. Tilley (Ed.), Evaluation for crime prevention. Crime prevention studies, volume 14 (pp. 93-118). Monsey, NY: Criminal Justice Press.

Eck, J. E., \& Weisburd, D. (1995). Crime places in crime theory. In J. E. Eck \& D. Weisburd (Eds.), Crime and place. Crime prevention studies, volume 4 (pp. 1-34). Monsey, NY: Criminal Justice Press.

Eisner, M., \& Wikström, P.-O. H. (1999). Violent crime in the urban community: a comparison of Stockholm and Basel. European Journal on Criminal Policy and Research, 7, 427-442.

Eksten, A. (2009). Misshandel mellan obekanta. Kan fler brott klaras upp? Del 2. In T. S. N. C. f. C. Prevention (Ed.), (pp. 65). Stockholm: The Swedish National Council for Crime Prevention.

Farrington, D. P. (1987). Evaluating area-based changes in policing strategies and laws. Police Studies: International Review of Police Development, 10(2), 67-71.

Felson, M., Berends, R., Richardsson, B., \& Veno, A. (1997). Reducing pub hopping and related crime. In R. Homel (Ed.), Policing for crime prevention: Reducing crime, public intoxacation and injury. Crime prevention studies, volume 7 (pp. 115-132). Monsey, NY: Criminal Justice Press.

Gabor, T. (1990). Crime displacement and situational prevention: toward the development of some principles. Canadian Journal of Criminology, 32(1), 41-74.

Graham, K., Leonard, K. E., Room, R., Wild, T. C., Pihl, R. O., Bois, C., et al. (1998). Current directions in research on understanding and preventing intoxicated aggression. Addiction, 93(5), 659-676.

Groff, E. R., Weisburd, D., \& Yang, S.-M. (2010). Is it important to examine crime trends at a local "micro" level?: a longitudinal analysis of street to street variability in crime trajectories. Journal of Quantitative Criminology, 26(1), 7-32.

Guerette, R. T. (2009). Analyzing crime displacement and diffusion. In U. D. o. Justice (Ed.), (Vol. 10): Center for Problem-Oriented Policing.

Guerette, R. T., \& Bowers, K. J. (2009). Assessing the extent of crime displacement and diffusion of benefits: a review of situational crime prevention evaluations. Criminology, 47(4), 1331-1368.

Hesseling, R. B. P. (1994). Displacement: A review of the empirical literature. In R. V. Clarke (Ed.), Crime prevention studies, volume 3 (pp. 197-230). Monsey, NY: Criminal Justice Press.

Homel, R., \& Clark, J. (1994). The prediction and prevention of violence in pubs and clubs. In R. V. Clarke (Ed.), Crime prevention studies, volume 3 (pp. 1-46). Monsey, NY: Criminal Justice Press.

Homel, R., Hauritz, M., \& Wortley, R. (1997). Preventing alcohol-related crime through community action: The surfers paradise safety action project. In R. Homel (Ed.), Policing for prevention: Reducing crime, public intoxacation and injury. Crime prevention studies, volume 7 (pp. 7-34). Monsey, NY: Criminal Justice Press.

Koper, C. S. (1995). Just enough police presence: reducing crime and disorderly behavior by optimizing patrol time in crime hot spots. Justice Quarterly, 12(4), 649-672.

Lawton, B. A., Taylor, R. B., \& Luongo, A. J. (2005). Police officers on drug corners in Philadelphia, drug crime and violent crime: intended diffusion and displacement impacts. Justice Quarterly, 22, 427-451.

McMurran, M. (1999). Alcohol and violence. Child Abuse Review, 8(4), 219-230.

Plant, M. A., Kreitman, N., \& Miller, T.-I. (1977). Observing public drinking. Journal of Studies on Alcohol, 38(5), 867-880.

Ratcliffe, J. H., Taniguchi, T., Groff, E. R., \& Woods, D. J. (2010). The Philadelphia foot patrol experiment: a randomized controlled trial of police patrol effectiveness in violent crime hot spots. Criminology, 49(3), 795-831.

Reiner, R. (2010). The politics of the police. New York: Oxford University Press.

Roncek, D. W., \& Maier, P. A. (1991). Bars, blocks and crimes revisited: linking the theory of routine activities to the empiricism of "hot spots". Criminology, 29(4), 725-753.

Rotton, J., \& Cohn, E. G. (2000). Weather, disorderly conduct and assaults: from social contact to social avoidance. Environment and Behavior, 32(5), 651-673.

Shaw, C. R., \& McKay, H. D. (1942). Juvenile delinquency and urban areas. Chicago, IL: University of Chicago Press.

Shearing, C. D., \& Stenning, P. C. (1983). Private security: implications for social control. Social Problems, 30(5), 493-506. 
Sherman, L. W. (1990). Police crackdowns: Initial and residual deterrence. In M. Tonry, \& N. Morris (Eds.), Crime and justice. An Annual review of research. (Vol. 12, pp. 1-48). Chicago: University of Chicago Press.

Sherman, L. W. (1995). Hot spots of crime and criminal careers of places. In J. E. Eck \& D. Weisburd (Eds.), Crime and place. Crime prevention studies, volume 4 (pp. 35-52). Monsey, NY: Criminal Justice Press.

Sherman, L. W., \& Weisburd, D. (1995). General deterrent effects of police patrol in crime hot spots: a randomized controlled trial. Justice Quarterly, 12(4), 625-648.

Sherman, L. W., Gartin, P. R., \& Buerger, M. E. (1989). Hot spots of predatory crime: routine activities and the criminology of place. Criminology, 27(1), 27-55.

Sherman, L. W., Shaw, J. W., \& Rogan, D. P. (1995). The Kansas City gun experiment. Research in brief. Washington, D.C.: National Institute of Justice, U.S. Department of Justice.

Smith, M. R. (2001). Police-led crackdowns and cleanups: an evaluation of a crime control initiative in Richmond, Virginia. Crime \& Delinquency, 47(1), 60-83.

Spelman, W. (1995). Criminal careers of public places. In J. E. Eck \& D. Weisburd (Eds.), Crime and place. Crime prevention studies, volume 4 (pp. 115-144). Monsey, NY: Criminal Justice Press.

Taylor, B., Koper, C. S., \& Woods, D. J. (2011). A randomized controlled trial of different policing strategies at hot spots of violent crime. Journal of Experimental Criminology, 7, 149-181.

Trojanowicz, R. (1986). Evaluating a neighborhood foot patrol program: The Flint, Michigan Project. In D. P. Rosenbaum (Ed.), Community crime prevention: Does it work? (pp. 157-178). Beverly Hills, CA: Sage.

Weisburd, D., \& Braga, A. A. (Eds.). (2006). Police innovation: Contrasting perspectives. Cambridge: Cambridge University Press.

Weisburd, D., \& Eck, J. E. (2004). What can police do to reduce crime, disorder and fear? The ANNALS of the American Academy of Political and Social Science, 593(1), 42-65.

Weisburd, D., \& Green, L. (1995). Policing drug hot spots: the Jersey City drug market analysis experiment. Justice Quarterly, 12(4), 711-734.

Weisburd, D., Bushway, S., Lum, C., \& Yang, S.-M. (2004). Trajectories of crime at places: a longitudinal study of street segments in the city of Seattle. Criminology, 42(2), 283-322.

Weisburd, D., Morris, N. A., \& Groff, E. R. (2009). Hot spots of juvenile crime: a longitudinal study of arrest incidents at street segments in Seattle, Washington. Journal of Quantitative Criminology, 25(4), 443-467.

Wikström, P.-O. H. (1995). Preventing city-center street crimes. In M. Tonry, \& D. P. Farrington (Eds.), Crime and justice. Strategic approaches to crime prevention. (Vol. 19, pp. 429-468). Chicago: University of Chicago Press.

Wikström, P.-O. H., \& Treiber, K. H. (2009). Violence as situational action. International Journal of Conflict and Violence, 3(1), 75-96. 